\section{Sprung from chains}

\section{Struther Arnott}

Principles of Nucleic Acid Structure. By Wolfram Saenger.

Springer-Verlag: 1984, Pp. 556. Pbk DM 79, \$29.50.

From time to time one reads a book or an account of an experiment and wishes, with more pleasure than envy, that one had produced it oneself. Wolfram Saenger's book is such a virtuoso production: wellwritten, 'profusely illustrated and astonishingly comprehensive. In it, fact and hypothesis are distinguished with rare scrupulousness. Any serious student or researcher will find it a mine of information. The merely curious now have a guidebook with which safely to explore the labyrinth of DNA and RNA structural studies.

Particularly praiseworthy is the way Saenger has managed to deal thoroughly but interestingly with all the fundamental business of conformational nomenclature and crystallographic esoterica. He has not failed to explore the many structural hypotheses still twisting slowly in the wind, but almost nowhere does he confuse these with experimentally well-founded models.

About a third of the book is devoted to exploring the nature and provenance of the polymorphism of DNA and RNA. Any polymer constructed with residues as complex as nucleotides should be extremely polymorphic. Even when restrained in plectonemically wound duplexes, with bases paired and stacked, polynucleotides have many degrees of structural freedom. Yet polymorphism in DNA and RNA structures has been persistently ignored or belittled, as a brief glance at history will show.

Astbury's early fibres were mixtures of A-DNA and B-DNA, but he interpreted their $\mathrm{X}$-ray patterns in terms of a single allomorph with the residue repeat of B-DNA $(0.34 \mathrm{~nm})$ and the structural repeat of A-DNA $(2.80 \mathrm{~nm})$. Then, during the renaissance of X-ray studies in the early 1950s, Franklin and Gosling established that DNA was at least dimorphic. Provocatively, they named their newer form A, and the form worked on earlier by Wilkins, B. During the long process of reconciling the Watson-Crick hypothesis with a tangible structure, attention was focused on the more hydrated $\mathbf{B}$ form, and A-DNA was forgotten until the 1960 s when RNA duplexes were discovered to have A-like structures. Despite conformational similarities the A structures are quite polymorphic, with helix pitches ranging from $2.8 \mathrm{~nm}$ to $3.9 \mathrm{~nm}$ and major grooves of strikingly variable widths. In the eponymous A-DNA this groove is clenched shut, excluding even water molecules, while in the A duplexes of largest pitch the major groove is wide enough to accommodate a third polynucleotide chain. B-DNAs have been shown to be just as polymorphic with pitches ranging from $2.4 \mathrm{~nm}$ to $3.6 \mathrm{~nm}$.

With Polonius-like retrospective wisdom one would expect the apotheosis of $\mathrm{A}$ and $\mathrm{B}$ polymorphism to be heteronomous duplexes in which one chain carries $\mathrm{C}^{\prime}$-endo-puckered deoxyribose rings like the $\mathrm{A}$ structures and the other carries $\mathrm{C}^{\prime}$-endo-puckered rings like $\mathrm{B}$. The synthetic duplex poly d(A). poly d(T) indeed has such a structure. (Sadly this particular allomorph arrived too late to catch the Saenger omnibus.) Heteronomous duplexes, unlike allomorphs with identical chains, are highly polar. Perhaps bidirectional sequences on DNA in chromosomes function as valves or direction markers.

Clearly the great variety of (righthanded) helical structures trapped in fibres before 1980 implies at least as great a variability in DNAs and RNAs in other milieux. Saenger's book certainly exposes us to variety in the catalogue of static structures, but the lively world of nucleic acids, rich in movement, bending, breathing, vibrating and shimmering is largely unexplored. Perhaps the frisson of the discovery of left-handed DNA will emphasize the reality of polynucleotide variety and variability - but perhaps not!

The possibility of left-handed polynucleotide duplexes was recognized early on: Maurice Wilkins explored sinister

\section{Magnetic mixture}

\section{Walton}

Rock and Mineral Magnetism.

By W. O'Reilly.

Blackie/Chapman \& Hall: 1984. Pp.220. f19.50, $\$ 45$.

A number of texts on rock magnetism have appeared over the past 20 years, but there is still a clear need for a solid, carefully written book on the subject. Sadly, this contribution does not fit the bill.

In general, the objective of books of this nature is to provide geophysicists with the information to be able to understand how the magnetic vector is produced in their samples. To do this it is essential first to understand the mineralogy, that is, the chemical and physical properties of the magnetic minerals and how these can change with temperature, pressure and chemical environment. Second, it is necessary to understand the physics - how the magnetic moments of individual grains arise, and how assemblies of such grains produce the resultant magnetic vector of the sample given the conditions of temperature, magnetic field, cooling rate and so on to which the sample was exposed.

Dr O'Reilly certainly meets the first of models of A- and B-DNA in the 1950s; later, others touted left-handedness for the D form of poly d(IC).poly d(IC), in hope, but erroneously. When a left-handed (Z) allomorph was eventually observed, ironically it indeed needed alternating purine-pyrimidine sequences. Z-like conformations have been observed with $d(G C)_{n} \cdot d(G C)_{n}, d(A C)_{n} \cdot d(G T)_{n}$ and $\mathrm{d}\left(\mathrm{As}^{4} \mathrm{~T}\right)_{\mathrm{n}} \cdot \mathrm{d}\left(\mathrm{As} \mathrm{s}^{4} \mathrm{~T}\right)_{\mathrm{n}}$ but not yet with $d(I C)_{n} \cdot d(I C)_{n}$ - nor with $d(A T)_{n} \cdot d(A T)_{n}$.

Depressingly, DNA is again being discussed in dimorphic terms; however now it is B and Z, not A and B! But Z-DNA is polymorphic too: relatively underwound duplexes with the peculiar dinucleotide motif of Z-DNA exist with residue rotations of $0^{\circ},-25^{\circ},-51^{\circ}$ as well as the $-60^{\circ}$ of the first left-handed structure.

Current X-ray structural studies focus on oligonucleotides in single crystals and in poly(oligonucleotides) in fibres. These structures are less regular. Whether or not the excursions from regularity are related to base sequences is a lively issue. More ambitiously - and perhaps more wisely there are increasingly successful studies of DNA bound to histones and other proteins which will reveal specifically how variety and variability in the genetic material can be exploited biologically. Among all its other riches, Saenger's book makes us aware of these too.

Struther Arnott is Vice President for Research and Dean of the Graduate School at Purdue University, Indiana.

these goals. There is a wealth of usefu in formation on the mineralogy of magnetic minerals; and while it is quite difficult to find the desired data, the fairly complete index mitigates the problem to a great extent.

Just as certainly, however, the book falls short of the second requirement: the mathematics is quite inadequate, with formulae simply being presented with no derivation and often supported by no reference. The equations are not numbered, often they are not displayed, simply appearing in the body of the text. Furthermore, the author is not only selective in his choice of references (perhaps understandably), but much of the literature he has opted to quote is oversimplified to such an extent that it is wrong. For example only one of Neel's famous papers is referred to, although these contain the basic physics and have not been superseded.

Neel's papers still form the basis for all rock magnetic theory. In discussing the physics of the subject, authors of textbooks would be well advised to begin with them. And if they intend to provide an accurate and reliable source of information for the uninitiated, it might be safer to end with them.

D. Walton is Professor of Physics at McMaster University, Hamilton, Ontario. 